\title{
Reanalyzing Definiteness in Bangla
}

\author{
PRIYANKA BISWAS \\ University of Southern California
}

\section{$1 \quad$ Introduction}

Definite descriptions in Bangla are expressed via two morpho-syntactic patterns, namely the bare classifier and the bare noun, discussed in detail in Simpson et al. 2011. The bare classifier form consists of a noun phrase and a classifier without a numeral, syntactically derived by NP-movement across the classifier ("NPraising"). In the bare noun form, there is no classifier or a numeral accompanying the NP. In this paper, I argue that two factors, "anaphoricity" and "uniqueness", play important roles in the selection of the pattern of the definite expression in Bangla. The NP-raising structure is used exclusively in anaphoric contexts, and shows similar properties to "strong article" definites cross-linguistically ( $c f$. Schwarz 2009). Uniqueness-based definites are expressed by bare nouns, which are otherwise similar in distribution to the "weak article" definites (Schwarz 2009). This paper contributes to our overall understanding of definiteness in Bangla, and of the cross-linguistic expression of anaphoricity and uniqueness aspects of definiteness.

In section 2, I present a description of the two strategies of forming definite descriptions in Bangla. Section 3 presents an overview of the two types of definites: "strong article" and "weak article" definites, as argued by Schwarz (2009). I present new Bangla data corresponding to the "bridging" uses of the definites, which are generally not accounted for in existing literature. Section 4 presents the links between the morpho-syntax and the semantics. Section 5 concludes the paper with suggestions for future work.

\section{$2 \quad$ Word Order and (In)definiteness}

Bangla (Bengali) is a South Asian language, spoken in parts of India and in Bangladesh. Unlike many other South Asian languages, Bangla has a set of numeral classifiers. Bangla classifiers (-Ta, -khana, -khani etc.) generally appear between the numeral and the noun (e.g., Ek-Ta boi 'one-Cla book'). The numeral- 


\section{Priyanka Biswas}

classifier combination precedes the noun phrase in the base word order [Num-Cla $\mathrm{NP}$ ], shown in $(1 \mathrm{a \& c})$. The numeral-classifier combination follows the NP in an alternative order [NP (Num-)Cla], as in (1b\&d). This is exemplified below:

(1)
a. Ek-Ta
One-cla
'A bird'
pakhi
bird
c. chO-Ta
six-cla
'Six birds'

\author{
b. pakhi-Ta \\ bird-cla \\ 'The bird'
}
d. pakhi chO-Ta
bird six-cla
'The six birds'

The base word order $(1 \mathrm{a} \& \mathrm{c})$ and the alternative order $(1 \mathrm{~b} \& d)$ are interpreted differently. The base order can have both strong and weak indefinite interpretations $^{1}$ (Dayal 2012). The alternative order, on the other hand, has a definite interpretation. $(1 \mathrm{~b}, \mathrm{~d})$ are the result of the same mechanism of NP-raising - the NP raises past the classifier, or past the numeral-classifier complex - and they have the same definite interpretation. The following table elaborates the distribution of classifiers inside nominal phrases and the resulting (in)definite interpretations corresponding to the different word orders.

Table 1: Classifiers in Bangla, their relative orders and interpretations

\begin{tabular}{|l|c|c|c|c|c|}
\hline Classifiers & $\begin{array}{c}\text { Num-cla N } \\
\text { (Base) }\end{array}$ & \multicolumn{2}{|c|}{ N-classifier (Alternative) } & $\begin{array}{c}\text { N Num-cla } \\
\text { (Alternative) }\end{array}$ \\
\hline default cla -Ta & Indefinite & Definite & Definite & Definite & Definite \\
\hline $\begin{array}{l}\text { Shape-specific } \\
\text {-khana }\end{array}$ & Indefinite & $x$ & $x$ & Definite & Definite \\
\hline -khani & Indefinite & $x$ & $x$ & Definite & Definite \\
\hline $\begin{array}{l}\text { Plural classifier } \\
\text {-gulo }\end{array}$ & $x$ & Definite & Definite & Definite & $x$ \\
\hline
\end{tabular}

\subsection{Definite Interpretation of the NP-raised Order}

The alternative order [i.e. NP (Num)-Cla] has been discussed extensively in the literature (Dasgupta 1983, Bhattacharya 1999, 2000, Ghosh 2010, Chacón 2010, Dayal 2012, Simpson et al. 2011). Bhattacharya argues that the alternative order

\footnotetext{
${ }^{1}$ See Dayal (2012) for a detailed account of Bangla classifiers. The paper presented at the BLS conference had several common observations with Dayal (2012). Dayal's paper was available after an earlier version of the BLS paper was submitted to the proceedings. The content has been modified in the current version of the paper to avoid repetition of the facts.

${ }^{2}$ Plural marking with a mass noun is possible in Bangla when it is coerced into a count noun.
} 


\section{Reanalyzing Definiteness in Bangla}

contributes to a specific reading. In his account, the NP moves to the specifier of a complex Numeral-Classifier head for checking an optional specificity feature. $\mathrm{He}$ refers to this movement as the NP-“object"-shift, owing to the similarity of this movement to that of VP-fronting. However, the alternative order has been argued to involve definiteness by others (Dasgupta 1983, Chacón 2010, Ghosh 2010, Simpson et al. 2011, and Dayal 2012). Modifying the original proposal of Bhattacharya (1999), Chacón (2010) provides an alternative account, where the NP moves to the specifier of the DP for checking a strong definite feature. A schematic representation of the NP-raising in a layered DP structure is given below:

$$
\left[{ }_{\mathrm{DP}}[\mathrm{NP}(\text { Adjective }) \text { Noun }] \mathrm{D}^{0}\left[_{\mathrm{NumP}}(\mathrm{Num})\left[_{\mathrm{ClaP}} \mathrm{Cla}\left[{ }_{\mathrm{NP}} \boldsymbol{t}_{N P}\right]\right]\right]\right]
$$

Note that the mechanisms for deriving (1b) and Error! Reference source not found.(1d) are the same, i.e. the NP moves past the Num-Cla to the Spec, DP. If the numeral is 'one', the definite form is [NP-Cla], in (1b), and it undergoes 'one' deletion (Dasgupta 1983). Otherwise, it is [NP Num-cla]. Dayal (2012) presents a set of tests that confirms the definite reading of the NP-raised order. Here I present one more test in support of this claim. The familiarity ${ }^{3}$ test for definiteness (Lyons 1999, von Heusinger 2002) requires the referent to be identifiable to both the speaker and the hearer. According to this diagnostic, the raised-NP is interpreted as a specific-definite, i.e. the referent is familiar to both the speaker and the hearer. These have similar features as the "strong article" definite, discussed later. This test confirms definite readings of the NP-raised order with respect to all classifiers. A summary is presented in table 2 .

Table 2: Base and alternative orders and their interpretations

\begin{tabular}{|l|c|c|c|}
\hline & Num-cla NP & NP-cla & NP Num-cla \\
\hline Familiar to speaker & yes/no & yes & yes \\
\hline Familiar to hearer & no & yes & yes \\
\hline Interpretations: & $\begin{array}{c}\text { Indefinite } \\
( \pm \text { specific })\end{array}$ & $\begin{array}{c}\text { Definite } \\
(+ \text { Specific })\end{array}$ & $\begin{array}{c}\text { Definite } \\
(+ \text { Specific })\end{array}$ \\
\hline
\end{tabular}

\subsection{Bare nouns and Definiteness}

The previous section shows that the NP-raised order leads to an interpretation of a definite description in Bangla. However, the bare noun can also be interpreted as a definite description, as discussed in detail in Simpson et al (2011). Simpson shows that, cross-linguistically, classifier languages (Hmong, Vietnamese, Cantonese and Bangla) show a relative scale of the use of bare nouns to express definiteness. The alternation between the bare nouns and the bare classifier

\footnotetext{
${ }^{3}$ The difference between identifiability and familiarity is not explicit in the literature. But, both of them refer to the knowledge of the speaker and the hearer regarding the referent of the NP.
} 


\section{Priyanka Biswas}

phrases (represented by the NP-raised order [NP-cla]) depends on the stage of grammaticalization the language has undergone in terms of expressing definiteness by means of the bare classifier phrase. Consider the following examples from Bangla showing definite uses of the bare noun:
a. kukur bagane Dakche dog garden-loc is-barking
'The dog is barking in the garden.'
\# 'Some $\operatorname{dog}(\mathrm{s})$ is/are barking in the garden.'
b. mina, dOrja bOndho, cabi kothae? Mina, door closed, key where 'Mina, the door is locked, where is the key?'

(Simpson et al. 2011, ex. (16c))
c. mukkhomontri chin-e gelen
prime-mininster China-loc went
'The Prime Minister went to China.'

Simpson et al. tests the judgments of speakers in five different contexts where definite determiners are generally used in determiner languages. The questionnaire is based on the following contexts of definiteness.

i. Discourse-anaphoric

ii. Visible, uniquely identifiable

iii. Association /inference

iv. Invisible, contextually unique

v. Culturally unique, familiar entities

Both types of definites, the bare classifier (or, the NP-raised order in Bangla) and the bare noun, are tested in each of the situations. Speakers' judgments shows preference of one form to the other in certain situations. I discuss the results in detail in section 4 . In the following section, I show that the NP-raised order and the bare NP correspond to two main interpretive types of definiteness.

\section{Two types of definites cross-linguistically}

A definite NP has the discourse pragmatic properties of familiarity (Karttunen 1976, Heim 1982 a.o.). In other words, a definite NP is discourse-old. The discourse-bound property generally corresponds to anaphoricity, i.e., the referent of the definite description is found in the previous discourse. Bangla nominals with the NP-raised order are always anaphoric and refer to entities in theprevious discourse. For example, the NP-raised order is infelicitous in a sentence that 


\section{Reanalyzing Definiteness in Bangla}

begins the discourse, as in (4a). Consequently, the NP-raised version is the only appropriate form in a continuing discourse, as in (4b).

a. gOtokal $\begin{aligned} & \text { ekTa } \\ & \text { chele-r } / * \text { chele-Ta-r }\} \text { Sathe alap holo } \\ & \text { 'I met a boy yesterday.' }\end{aligned}$
b. $\{$ chele-Ta $/ *$ Ek-Ta $\quad$ chele $\}$ triathlon champion
\{boy-cla /one-cla boy triathlon champion
'The boy is a triathlon champion.'

Uniqueness is another criterion for definiteness: the referent of a definite nominal phrase needs to be uniquely identifiable to the speaker and the hearer. No reference to the prior discourse is required. The unique referent is the most salient in the current context. Uniqueness is also satisfied by the criterion of anaphoricity, except that the antecedent of the anaphor needs to be present in the immediate discourse, while uniqueness involves maximal reference with respect to the current context. Based on these approaches, Schwarz (2009, to appear) presents an elaborate cross-linguistic account where the different aspects of the semantics of definiteness receive a different syntactic expression. In what follows, I summarize the syntactic encoding of the two types of definite interpretations and present a new perspective for understanding definiteness in Bangla.

\section{1 "Strong article" definites: Anaphoricity}

As mentioned above, anaphoricity requires the definite description to refer back to a linguistic expression that is mentioned in a previous discourse (Christophersen 1939, Heim 1982, Kamp 1981). Schwartz provides crosslinguistic evidence to show that languages often use a "strong" form of the definite article in anaphoric contexts. For example, between the two types of definite articles in the Frisian dialect of Fering, only the "strong" form is used to convey the anaphoric use (Ebert 1971). In other languages, such as Akan, which has only one overt determiner, it is used in the anaphoric contexts; elsewhere a bare noun is used. Similar pattern is noticed in Bangla for the NP-raised version of the definite description. That is, the NP raising is associated with anaphoric interpretation and corresponds to the "strong article" definite crosslinguistically.

\section{2 "Weak article" definites: Uniqueness}

The uniqueness approach is based on the idea that the referent of a definite description has a property that is unique, in general or in a contextual situation, and is sorted out by an appropriate description. A definite description in an anaphoric situation is also unique; however, anaphoricity is not an absolute criterion for uniqueness. For example, the referent of the Prime Minister matches 


\section{Priyanka Biswas}

the descriptive content of the definite description without any reference to the previous context. Uniqueness in languages can be expressed through various ways. Schwarz (2009) provides several instances of "situational uniqueness." For

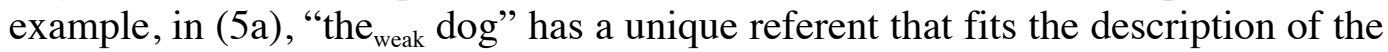
noun phrase, when it is uttered in a situation where the referent - a single dog - is present.

(5) A hünj hee tuswark.

'The dog has a tooth ache.' (Schwartz 2009, originally from Ebert 1971)

b. Sabdhan! kukur-Ta kamRate pare

Beware! Dog-cla bite-ppl can

'Beware! The dog might bite you!'

Similarly is the case for the "larger situation" definites (e.g., the king, the President etc.). The referent is unique where it is part of a larger situation (e.g., the President of America). Culturally unique definites (e.g., the king) and the globally unique ones (e.g, The Moon) are also cases of situational uniqueness. Corresponding Bangla examples are given below.

(6) a. The President urged for peace.

$\begin{array}{llll}\text { b. rasTropoti- }(* \text { Ta) } & \text { Santisthapon-er } & \text { barta } & \text { dilen } \\ \text { President- }(* \text { cla }) & \text { make-peace } & \text { message } & \text { gave } \\ \text { 'The President sent a message of peace.' } & & \end{array}$

(7) a. Armstrong was the first one to fly to the Moon.

b. armstOng prothom cMad-(*Ta)-e pa dilen Armstrong first moon-(*cla)-loc foot gave

'Armstrong stepped on the Moon first.'

Consider that in Bangla, the NP-raised order is infelicitous in the "larger situation" use (6b), and in the global situation use in

(7b), whereas, the definite NPs in English are felicitous in such cases. Schwarz (2009) reports, from a cross-linguistic study, that definiteness based on uniqueness prefers the "weak article" (e.g., Fering, German, Lakhota, Hausa etc.), or the bare nouns (Maurutian Creole, Akan etc.). Similarly, Bangla shows patterns of the latter group of languages where the definite article is predominantly used in the anaphoric contexts (Schwarz 2009). Only the bare nouns are felicitous in the uniqueness situations. The former group utilizes the weak articles in such cases. Note that the unique cases discussed in this section have an indirect connection to the discourse, unlike the straightforward link the anaphoric cases have. 


\section{Reanalyzing Definiteness in Bangla}

\section{3 "Bridging" definites}

Schwarz (2009) discusses a third type of definite, "bridging" (also called "inferable" in Prince 1981). The context in the bridging cases has a very indirect connection to the discourse, and generally, it does not fit into the major approaches to definiteness described in the previous section. Schwarz distinguishes two classes of bridging use which relate to the context differently. In brief, the bridging cases are divided into (a) "part-whole bridging", and (b) "producer-product bridging". Cross-linguistically, the "part-whole" (e.g., crisperfridge, kitchen-house, trunk-car etc.) is expressed by a weak article, while the "producer-product" (e.g., author-book, painter-painting etc.) is expressed by a strong article. Schwarz elaborates that in the first case, the entity (e.g., fridge) can be considered as the antecedent for bridging, while the part of the antecedent (e.g., crisper) as the "bridged" definite. In the latter case, the "producer" (e.g., author) is inferred from the "product" (e.g., play). Examples corresponding to the two cases, reflecting the article use in German, are given below (from Schwarz 2009, ex. (58) and (59), pp. 52-53).

(8) a.The fridge was so big that the pumpkin could be stowed in the $\left\{\mathbf{i m}_{\text {weak }} /\right.$ \#in $\left.\mathbf{d e m}_{\text {strong }}\right\}$ crisper without a problem.

b. The play displeased the critic so much that he tore the $\left\{\# \mathbf{a m}_{\text {weak }} /\right.$ an $\left.\mathbf{d e m}_{\text {strong }}\right\}$ author to pieces in his review.

Such "bridging" cases involve an alternation between the NP-raised word order and bare nouns in Bangla. Consider the following examples in Bangla.

\begin{tabular}{|c|c|c|c|c|}
\hline $\begin{array}{l}\text { a.frij-Ta } \\
\text { fridge-cla }\end{array}$ & so & $\begin{array}{l}\text { Eto } \\
\text { big }\end{array}$ & & \\
\hline $\begin{array}{l}\text { doRja-*(Ta } \\
\text { door-cla }\end{array}$ & $\begin{array}{l}\text { du } \\
\text { two }\end{array}$ & $\begin{array}{l}\text { hat-e } \\
\text { hand-loc }\end{array}$ & $\begin{array}{l}\text { khulte hOe } \\
\text { open be }\end{array}$ & \\
\hline 'The fridge $\mathrm{i}$ & so bi & hat the doo & eds to be op & ed by two hand \\
\hline $\begin{array}{l}\text { b. naTok-Ta } \\
\text { play-cla }\end{array}$ & $\begin{array}{l}\text { eto } \\
\text { so }\end{array}$ & $\begin{array}{l}\text { bikkhEto } \\
\text { popular }\end{array}$ & $\begin{array}{l}\text { hoyeche } \\
\text { been }\end{array}$ & $\begin{array}{l}\text { je } \\
\text { COMP }\end{array}$ \\
\hline $\begin{array}{l}\text { poricalok-( } \\
\text { director-cla }\end{array}$ & \#Ta) & $\begin{array}{l}\text { nije-i } \\
\text { self-emph }\end{array}$ & $\begin{array}{l}\text { Obak } \\
\text { astonished }\end{array}$ & $\begin{array}{l}\text { hoye-gEchen } \\
\text { become }\end{array}$ \\
\hline $\begin{array}{l}\text { 'The play ha } \\
\text { astonished.' }\end{array}$ & s been & o popular tl & he director 1 & aself has becom \\
\hline $\begin{array}{l}\text { oSudh-Ta-1 } \\
\text { medicine-c }\end{array}$ & 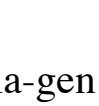 & $\begin{array}{l}\text { parSo-prot } \\
\text { side-effect }\end{array}$ & & \\
\hline
\end{tabular}




\title{
Priyanka Biswas
}

\author{
tai kompani-(Ta) o-Ta bajar-theke tule-niyeche \\ thus company-cla that market-from withdrew \\ 'The side-effects of the medicine are fatal, so the company has \\ withdrawn it from the market.'
}

Given the cross-linguistic similarity and the morpho-syntactic processes of expressing definiteness in Bangla, the "part-whole" relation would be predicted to involve bare noun, while the "producer-product" would involve NP-raising. However, the "part-whole" relation in Bangla involves the NP-raised version as in (9a), whereas, the "producer-product" relation involves an alternation between the NP-raised form and the bare noun, shown in (9b-c). The classifier -Ta on human nouns often has a pejorative connotation, for example, director in (9b). Thus, an alternative (e.g., company in (9c)) shows that alternation between the two forms of definites is found in Bangla.

\section{$4 \quad$ Two strategies}

Simpson et al. (2011) reports average acceptability rate of the two types of definite descriptions in five contexts, as mentioned earlier. In a 5-point scale where 5 is 'completely acceptable', the highest acceptability rate of the NP-raised version is in the "discourse-anaphoric" and "visible, uniquely identifiable" contexts [average rate 4.81/5 and 4.82/5, respectively]. The highest average rate of the bare nouns are in the "invisible, contextually unique" and "culturally unique, familiar" contexts [average rate $4.18 / 5$ and $4.86 / 5$, respectively]. The acceptance rate of the NP-raised version in the "association/inference" context is $4.35 / 5$, whereas, the average rate of the bare nouns in the same is 3.73/5.

A comparison between the average ratings relative to the contexts where the two types of definites occur suggests that the two types of definites are selected on the basis of the context. More specifically, the NP-raised version marks anaphoric definites, (and probably deictic as well). Any referent that is salient in the context, either by virtue of a continuing discourse, or by sensory perception (e.g., referring to a chair when the speaker and the listener are in the same room), i.e. the "visible uniquely identifiable cases", prefers a "strong article" definite or an NP-raised version in Bangla. When the referent is not contextually salient, but uniquely identifiable given world knowledge (e.g., The Sun), the bare noun is utilized. As cross-linguistically attested, the strategy of the "weak article" or bare noun definite depends on the referent being salient, but not by the current context.

The alternation of the NP-raised definite and the bare noun definite corresponds to what Schwarz describes as the "bridging" cases. As shown in the examples in (9), Bangla utilized the NP-raising in the "part-whole" definite, but has an alternation between the two forms in the "producer-product definite" cases. I conjecture that this is the reason behind the relative high average rating of both forms in Simpson's study (i.e. 4.35/5 for NP-raised definite, 3.73/5 for the bare noun definite) in the context of "association/inference". I predict that a two-way 


\section{Reanalyzing Definiteness in Bangla}

classification of these cases, in terms of the "part-whole" and "producer-product" would yield clearer ratings.

In sum, we saw that the NP-raised word order is mandatory in the anaphoric reading, whereas the bare noun is used when uniqueness alone is at work. This indicates that the NP-raised word order in Bangla is the "strong article" definite and it requires the NP to move to the Spec, DP. The "weak article" definites are definite by uniqueness. Simpson provides possible explanations for the preference of the bare-classifier cases (NP-raised) in some contexts. For Bangla, it is possible that the NP-raised form might have other semantic contributions as well. Such as, this form naturally incurs a contrast or focus on the referent. Nevertheless, anaphoricity plays the main role in choosing the NP-raised version in Bangla.

\section{$5 \quad$ Conclusion}

This paper establishes a link between two ways of forming definites and two approaches to interpret it. It has been argued that Bangla has two strategies of forming definite descriptions. Generalizations on definiteness from previous work on classifier languages (Simpson et al. 2011) and crosslinguistic classification of definites (Schwarz 2009) suggest that there are two main interpretive effects associated with definiteness that are reflected in the morpho-syntax of definite nominals. Anaphoricity plays a major role in the so-called "strong article definite" use, which is parallel to the NP-raised form or the bare classifier form in Bangla. Non-anaphoric definite descriptions mostly utilize the "weak article" or the bare noun cross-linguistically. The discussion on Bangla definites adds to the recent body of work on definiteness. This paper establishes a cross-linguistic link between the definiteness strategies and leaves space for future comparative work on definiteness.

\section{Acknowledgments}

Special thanks to Roumyana Pancheva for helpful suggestions. The paper has also benefitted from suggestions by Andrew Simpson, Audrey Li, Barry Schein and Hagit Borer, as well as the audience of Syntax+ at the University of Southern California and the $38^{\text {th }}$ Berkeley Linguistic Society. Of course, all errors are mine.

\section{References}

Bhattacharya, Tanmoy. 1999. Specificity in the Bangla DP. In R. Singh, ed., Yearbook of South Asian Languages and Linguistics 2, 71-99. New Delhi/London: Sage Publications.

Bhattacharya, Tanmoy. 2000. In search of the vague 'One.' In Tina CambierLangeveld, Anikó Lipták, Michael Redford and Erik Jan van derTorre, eds., ConSOLE 7, 33-48. Leiden: SOLE. 


\section{Priyanka Biswas}

Biswas, Priyanka. 2011. Pseudo-noun Incorporation in Bangla. Handout in Formal Approaches to South Asian Languages (FASAL I), University of Massachusetts, Amherst. March 2011.

Chacón, Dustin A. 2010. Classifying Bengali as South Asian. Manuscript. University of Minnesota. Published as: Head Movement in the Bangla DP. Journal of South Asian Linguistics, 4:3-24.

Christophersen, Paul. 1939. The articles: A study of their theory and use in English. Munksgaard, Copenhagen.

Dasgupta, Probal. 1983. On the Bangla classifier Ta, its penumbra, and definiteness. Indian Linguistics 44:10-26.

Dasgupta, Probal \& Rajat Ghosh. 2007. The nominal left periphery in Bangla and Asamiya. In R. Singh, ed. Annual Review of South Asian Languages and Linguistics 2007, Pp 3-29. Berlin: Mouton De Gruyter.

Dasgupta, Probal. 1992. Pronominality and Deixis in Bangla. Linguistic Analysis, 22: 61-77.

Dayal, Veneeta. 2011. Hindi Pseudo-noun Incorporation. Natural Language and Linguistic Theory 29.1, 123-167.

Dayal, Veneeta. 2012. "Bangla Classifiers: Mediating between Kinds and Objects", Italian Journal of Linguistics 24.2.

Ghosh, Rajat. 2010. Some Aspects of Determiner Phrase in Bangla and Asamiya. Saarbrucken, Germany: LAP.

Hawkins, J. A. 1978. Definiteness and Indefiniteness. Croom Helm, London.

Heim, Irene. 1982. The semantics of definite and indefinite noun phrases, $\mathrm{PhD}$ thesis, University of Massachusetts.

von Heusinger, Klaus. 2002. Specificity and definiteness in sentence and discourse. Journal of Semantics 19: 245-274.

Jackendoff, Ray. 1977.X-bar syntax. Cambridge MA: MIT Press.

Kamp, Hans. 1981. A theory of truth and semantic representation, in J. 


\section{Reanalyzing Definiteness in Bangla}

Karttunen, Lauri. 1976. Discourse referents. In J. McCawley, ed., Syntax and semantics 7: 363-385. New York: Academic Press.

Longobardi, Gennarro. 1994. Reference and proper names: A theory of $\mathrm{N}$ movement in syntax and logical form. Linguistic Inquiry 25.4: 609-665.

Prince, Ellen. F. 1981. Toward a taxonomy of given/new information. In P. Cole, ed., Radical Pragmatics, 223-255. Academic Press, New York.

Roberts, Craige. 2003. Uniqueness in definite noun phrases, Linguistics and Philosophy 26.3: 287-350.

Schwarz, Florian. 2009. Two Types of Definites In Natural Languages. Ph. D. thesis, University of Massachusetts, Amherst.

Schwarz. Florian. (to appear). Different Types of Definites Crosslinguistically. Draft 2012. Downloaded from http://www.florianschwarz.net/wpcontent/uploads/2007/08/CrossLingDef.pdf , May 2012.

Simpson, Andrew, Hooi Ling Soh \& Hiroki Nomoto. 2011. Bare Classifiers and Definiteness. In Studies in Language 35:1, 168 - 193. John Benjamins Publishing Company.

Priyanka Biswas

University of Southern California

Department of Linguistics

Grace Ford Salvatori 301

Los Angeles, CA 90089-1693

pbiswas@usc.edu 